\title{
Squamous papilloma of the anal canal
}

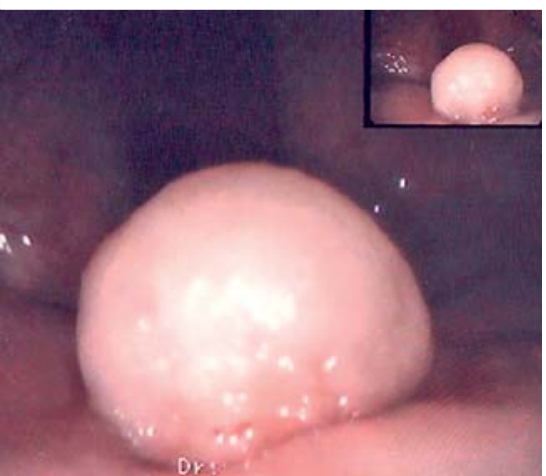

Fig. 1 Sessile anal polyp seen on retroflexion of the scope.

Squamous papillomas of the gastrointestinal tract are usually limited to the oral cavity [1], oropharynx [1], and the esophagus [2,3]; squamous papilloma of the anal canal is a rare entity. We report a case of a squamous papilloma of the anal canal, initially suspected to be a fibroepithelial anal polyp.

An asymptomatic 60-year-old man underwent screening colonoscopy because of a strong family history of colonic polyps. Total colonoscopy was normal but retroflexion of the scope in the rectum revealed a 5-mm, sessile, nodular anal polyp ( $\bullet$ Fig. 1), which felt rigid when taking biopsy samples with cold forceps. Initially, a fibroepithelial anal polyp was suspected, but histopathological examination revealed fragments of mature squamous epithelium, which were of normal thickness and parakeratinized, without underlying fibrovascular stroma. Focally the lesion was slightly hypertrophic. The basal layer showed undulation, and regular polarity and cellular organization. Low mitotic activity was present in the basal and parabasal layers only, while the upper layers exhibited degenerative changes. A few binuclear cells were found. Some of the detached, smaller fragments resembled tips of fingerlike papillary projections. There were no signs of dysplasia or malignancy ( $\bullet$ Fig.2). Human papilloma virus (HPV) was not detected in the biopsy samples using p16 immunostaining as a surrogate marker ( Fig.3). An index colonoscopy done at age 50 was completely normal. As the patient was asymptomatic, no endoscopic or surgical resection was carried out.

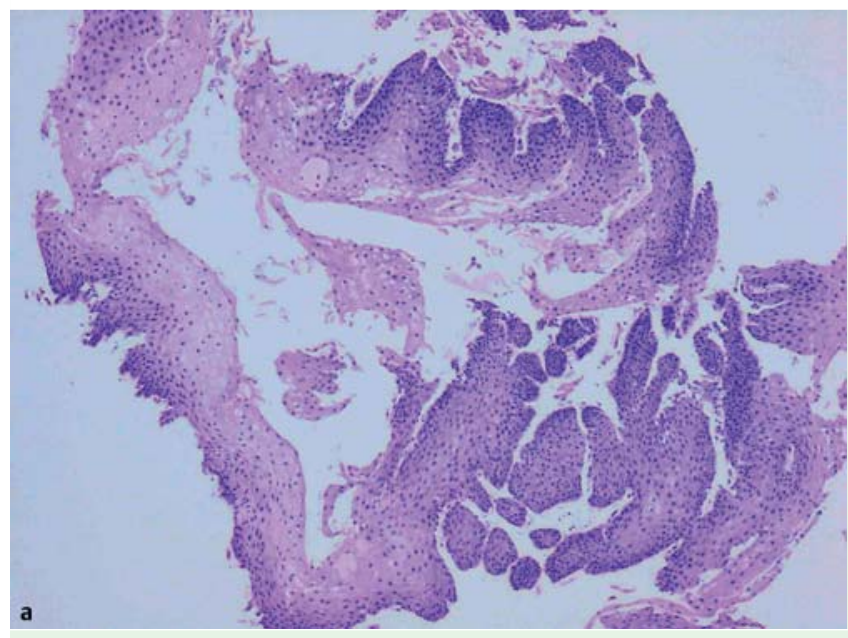

Fig. 2 a Fragments of papillomatous squamous epithelium with focal papillary projections (magnification $\times 5)$. b Squamous cells showing degenerative changes (cytoplasmic vacuolization); a binuclear cell is seen (arrow; magnification $\times 10$ ).

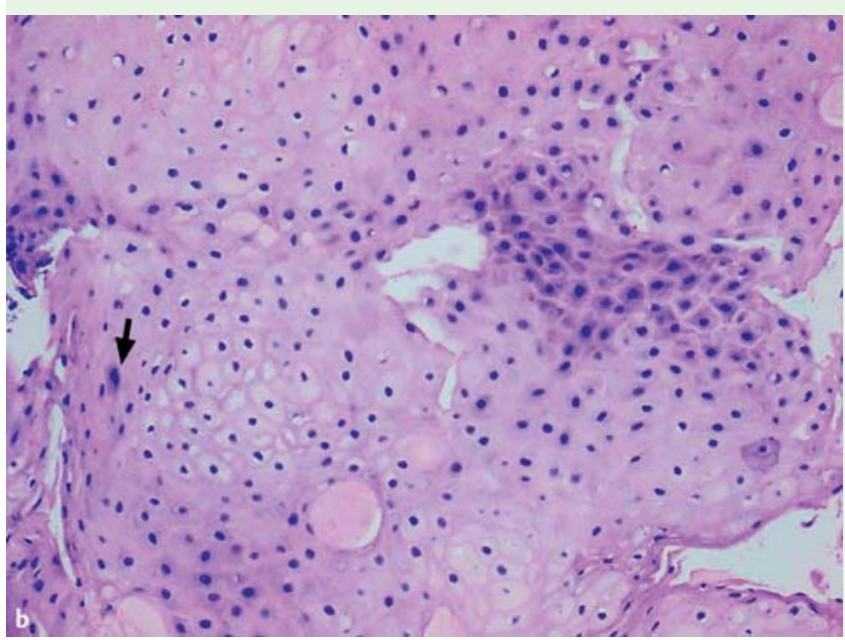

Fig. 3 Negative p16 immunostaining used as a surrogate for human papilloma virus (magnification $\times 5$ ).

Squamous papilloma of the anal canal is a rare benign epithelial neoplasm that can be mistakenly suspected to be a fibroepithelial anal polyp. The tumor is characterized by papillomatous processes and covered by keratinized squamous epithelium
[4]. HPV negative lesions are also commonly regarded as 'burned-out' condylomas [4]. It is important for colonoscopists to keep such lesions in mind when considering the differential diagnosis of an anal polyp. 
Endoscopy_UCTN_Code_CCL_1AD_2AC

\section{Competing interests: None}

\section{J. Gerada ${ }^{1}$, A. Savic ${ }^{2}$, M. Vassallo}

${ }^{1}$ Division of Gastroenterology, Mater Dei Hospital, Malta

${ }^{2}$ Department of Histopathology, Mater Dei Hospital, Malta

\section{References}

1 Karantanis D, Allen-Auerbach M, Czernin J. Squamous papilloma of the oral cavity and oropharynx on 18F-FDG PET/CT imaging. Clin Nucl Med 2012; 37 (Suppl. 05): e98-99

2 Kanth P, Go MF. Squamous papilloma: an unusual esophageal entity. Endoscopy 2011; 43 UCTN (Suppl. 02): E405 - 406

3 Rebeuh J, Willot S, Bouron-Dal SoglioD et al. Esophageal squamous papilloma in children. Endoscopy 2011; 43 UCTN (Suppl. 02): E256

4 Hamilton SR, Aaltonen LA eds. World Health Organization classification of tumours. Pathology and genetics of tumors of the digestive system. Lyon: IARC Press; 2000: $147-$ 155

\section{Bibliography}

Dol http://dx.doi.org/ $10.1055 / \mathrm{s}-0032-1325892$ Endoscopy 2013; 45: E42-E43 (C) Georg Thieme Verlag KG Stuttgart · New York ISSN 0013-726X

Corresponding author DrJ. Gerada

Mater Dei Hospital

Msida

Malta

Fax: +356-25-457582

jurgen.gerada@gmail.com 